\title{
Roland Barthes e a anatomia palimpséstica
}

\author{
Cristiano Bedin da Costa'
}

RESUMO: Em Roland Barthes por Roland Barthes, recebemos a seguinte indicação de leitura: "Tudo isso deve ser considerado como dito por um personagem de romance". A frase, ao introduzir aquilo que Eric Marty define como um jogo carnavalesco em que o "eu", o "ele" e o "vós" alternam-se constantemente, desorganiza o discurso autobiográfico regulado pelas prescrições modernas, fazendo da obra um verdadeiro patchwork: reescrituras, acréscimos, obliterações em meio aos livros, aos temas, às lembranças, de modo que essa nova enunciação não permite saber se é do presente ou do passado que se fala, tampouco se é mesmo da vida daquele que escreve que se diz. Para Françoise Caillard, isso se deve ao fato de que a biografia Barthesiana não toma o bios enquanto representante do vivido, mas sim da vida no que tem de mais orgânico: 0 corpo em suas constantes dilatações e invenções. De fato, em Barthes, o corpo é sempre atópico, incapaz de ser apreendido em sua totalidade. Nele, há sempre um excesso, um rasto insignificante, um mais além de todo sentido. Escrevê-lo, portanto, é participar de uma dispersão: em meio à música, à literatura, à fotografia, ao cotidiano. Esse excesso, essa mistura anti-hierárquica de linguagens e afectos compondo uma anatomia palimpsesticamente impura, é o que aqui deverá nos interessar.

PALAVRAS-CHAVE: Roland Barthes; Corpo; Escrita; Palimpsesto

\section{Roland Barthes and the palimpsest anatomy}

ABSTRACT: In Roland Barthes by Roland Barthes, we are given the following reading advice: "All must be considered as if spoken by a character in a novel". The sentence, on introducing what Eric Marty has defined as a carnival game in which "I", "he" and "you" constantly alternate, disorganizes the autobiographic discourse regulated by modern prescriptions, thus turning the work into a real patchwork: re-writings, additions, obliterations amidst books, subjects, memories, so that the new enunciation prevents us from knowing whether it talks about the present or the past, let alone whether it really talks about the writer's life. For Françoise Gaillard, this is due to the fact that Barthesian biography does not regard the bios as representing what has been lived, but life in what it has of the most organic: the body in its constant dilations and inventions. In fact, in Barthes, the body is always atopic, unable to be apprehended in its totality. There is always an excess in it, an insignificant trace, something beyond any sense. Therefore, writing about is to participate in dispersion: amidst music, literature, photography, daily life. Such excess, such anti-hierarchical combination of languages and affects composing a palimpsestically impure anatomy is what will interest us here.

KEYWORDS: Roland Barthes; Body; Writing; Palimpsest.

\footnotetext{
Psicólogo; Doutor em Educação; Docente no Centro Universitário Univates/Lajeado/RS. E-mail: cristianobedindacosta@hotmail.com.
} 


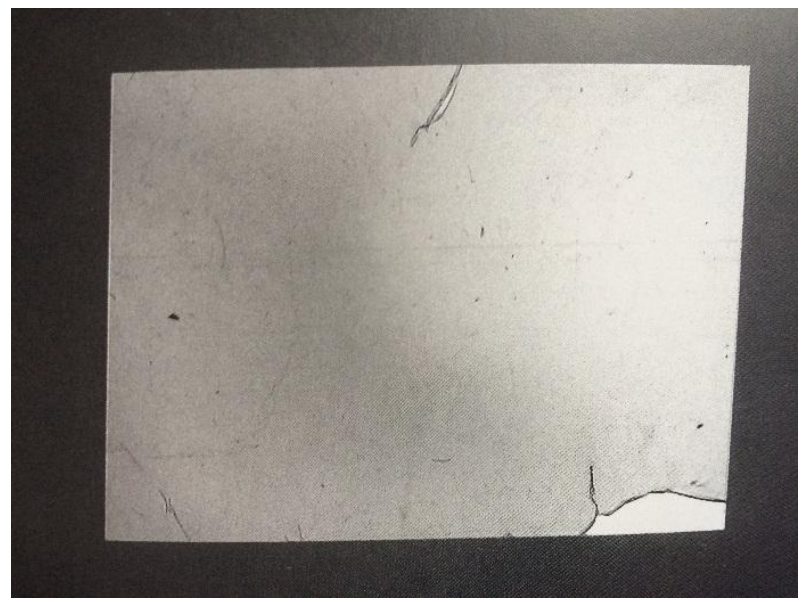

Mario Garcia Torres, December 2007, 2007.

Dezembro de 2007.

Permitam-me marcar essa data, esse mês nesse ano, como ponto inicial de minha fala. Os 31 dias de dezembro de 2007, tal como registrados pelo mexicano Mario Garcia Torres. Trata-se de uma imagem apenas, um único slide, no qual está projetado o negativo páb que o artista carregou no bolso durante o período indicado pelo nome da obra. Das 744 horas do mês, de todo o vivido nesses 31 dias, são conservados apenas alguns rastros involuntários, oferecidos em forma de riscos, de pequenas ranhuras na superfície branca.

0 desejo do artista, a obra como vontade, sua realização.

it também o acidente, o indeterminado, a mão da sorte.

[não dois lados, tampouco o segundo como consequência do primeiro, mas sim: sua condição de possibilidade].

"Entrar numa arte por meio de outra" (BARTHES, 2005, p.144): em 17 de fevereiro de 1979, era com essas palavras que Roland Barthes iniciava sua aula, na qual a fotografia servia como matéria para a preparação do romance. Hoje, a deriva desse dezembro de 2007 não funciona como simples alegoria, embora não vá merecer, de minha parte, nenhum exame. Tomo-a como um guia iniciático, uma vez que a atmosfera que a envolve não deixa de intoxicar o que vem a seguir. De certo modo, o pouco que direi dessa singular anatomia na qual o corpo não se define por ossos, articulações, rosto e membros, mas sim por sucessivas raspagens e reescrituras, está dito, por outros meios, nesse negativo e nos vestígios que 0 atravessam.

Enquanto palimpsesto, o corpo se constitui por atravessamentos, por contágios, por recomeços. Trata-se de uma existência impura e, diríamos até, imperfeita, visto que necessariamente inacabada. "Que direito tem meu presente de falar de meu passado?" (BARTHES, 2003, p.137); "Que é este "você' com o qual você se pareceria ou não?" (BARTHES, 2003, p.48).

Eis, desde já, aquilo no que acreditamos (eu e vocês, se me acompanharem): a cada recomeço, escrita é uma rasura no nome. Uma tentativa - permitam-me citar alguém como Mike Tyson - de acertar a ponta do próprio nariz, de modo a enfiar (o termo deve ser mesmo esse, rasteiro) o osso no cérebro. Da cara ao descaramento. Da máscara a massa amorfa de carne.

Trata-se de uma ideia simples: "simples como uma ideia de suicídio" (BARTHES, 2003, p.71). 
Inimitável: eis o estatuto do corpo em Roland Barthes. Não nomeio um sujeito: delimito um meio, ou, se preferirmos, a coerência interna de um pensamento. Do homem Barthes semiólogo, hedonista, canhoto, francês pelas frutas, morto em 1980 (ano, aliás, de meu nascimento) - nada a dizer a não ser isso: ele não me interessa $\rightarrow$ [a precisão é importante: opero como pedaços, fragmentos dispersos. Se preferirem: com as partes de Barthes que me tocam. Por isso - obviamente - pago um preço, que é o de perder a noção do todo. No entanto, acredito que essa espécie de política das friç̧ões, em se tratando do corpo, éperfeitamente justificada. Além disso, para essas frases, para essas lufadas de linguagem que me tocam, nem sempre tenho referências, e não vejo razão para buscá-las. Para o desejo, sabemos, interessa apenas o agora] $\rightarrow$ Nesse sentido, do meio barthesiano do qual aqui me ocupo, aproximo-me por uma sedução, por um estranho arrebatamento, um incômodo. Trata-se certamente de uma aventura, no sentido exato em que aquilo que me anima é sempre da ordem do imprevisível, do quebrado, do descontínuo, do incerto. No entanto, nenhum saber, nenhuma ciência ou cultura parece funcionar bem como guia, até porque é a partir do emudecimento desses discursos (científicos e culturais) que o corpo, em Barthes, torna-se possível.

\section{Ler Barthes através de um conflito: o corpo versus seus fantasmas}

[é justamente isso o que encontramos em Roland Barthes por Roland Barthes: a palavra corpo destacada como palavra-maná, a palavra "cuja significação ardente, multiforme, inagarrável e como que sagrada" (Idem, p.146), dá a ilusão de que, com ela, se pode responder a tudo. Não se trata de uma palavra central, mesmo que certamente não seja periférica. Trata-se de uma palavra nunca devidamente instalada, sempre atópica, que desabrocha na obra aos poucos, ao livrar-se do peso da verdade histórica - mesmo em uma autobiografia - e da validade dos sistemas e das estruturas analíticas. "Tudo isso deve ser considerado como dito por um personagem de romance" (Idem, s/p): a indicação é precisa: o que se diz e mostra, o que se seguirá, aos pedaços e textualmente, não diz respeito ahistoriadores, anatomistas e fisiologistas, não obedece à ordem dos fatos, mas configura um outro corte, recebe uma outra nomeação. "Escrever o corpo. Nem a pele, nem os músculos, nem os ossos, nem os nervos, mas o resto: um isto balofo, fibroso, pelucioso, esfiapado, o casacão de um palhaço" (Idem, p.199)].

Mas o que quer dizer, então, esse resto?

0 que se lê nesse patchwork colorido, inquieto, polifônico?

0 que quer dizer o corpo?

Em um sentido tópico, ele indica um isolamento. Ter um corpo, testemunhar por ele, é sempre habitar uma solidão, visto que é em oposição ao todo, ao contrato social, que um corpo se constitui. Não se trata de um confronto, mas antes de uma espécie de acaso: a arquitetura corpórea obedece a um lance de dados, trabalha ao sabor de ideias outras que não as daquele que diz eu. Lembremo-nos d'A câmara clara, e do princípio heurístico que conduz sua investigação: o que meu corpo sabe da fotografia? 0 corpo, não o eu. A carne, não a razão. A natureza, não a cultura.

As oposições binárias não são neutras, indicam a afirmação de um ethos comum, mesmo que (em certo aspecto) infeliz: antes de qualquer coisa, o corpo é aquilo que não se compartilha, não se iguala, não encontra correspondências. Em última análise, meu corpo, aconteça o que acontecer, estejamos nós onde estivermos, não é, não foi e não será igual ao teu. 


\section{Pelo corpo, estamos sozinhos e isso é tudo}

Não se trata de um isolamento voluntário. Não se trata da construção de barricadas, da delimitação de limites seguros para a instauração de uma identidade. Nesse ponto, a distância não é relativa apenas a um e outro sujeito. 0 corpo é sempre um pouco mais e um pouco menos, ou seja, dança sua própria dança, enovela-se, espreguiça-se, acorda, fere, bate, retesa-se, estende-se, desloca, treme, ressoa, acentua-se, estilhaça-se, não se aguenta. Tais movimentos são aquilo que podemos ler em "Rasch", "Amar Schumann" e "Música prática", escritos talvez menores, mas que funcionam como uma cartografia precisa do corpo em estado de música, o corpo enquanto matéria para uma semiologia segunda, ocupada com o formigamento das pancadas (e não com o sistema das notas, dos tons, dos acordes, dos ritmos).

Problema de escuta, ou melhor, a escuta como singular arquitetura anatômica, condição de possibilidade para um corpo: ao desconstruir-se, ao distanciar-se da decifração, do reconhecimento, da busca pelo sentido através da aplicação ao código, a escuta é sempre um lançar-se para fora, é tornar-se exterior, ou seja, renunciar a uma intimidade. Isto vale para o olhar, e isto vale, também, para a leitura. O prazer do texto, "0 terceiro sentido", "Escrever a leitura", "Réquichot e o seu corpo": dentro da obra barthesiana, inúmeras são as tentativas de dar consistência ao dilaceramento; de abrandar, pela tessitura das palavras, os sopros, os espasmos, os delírios do corpo.

Procedimento ético, sem dúvida. "A ciência é grosseria, a vida é sutil" (BARTHES, 2007a, p.18): eis o que aprendemos na Aula. Se formos mesmo científicos por falta de sutileza, falta-nos também vida, certa dimensão da vida; falta-nos algo. Sabe-se que é desse algo impessoal, desse drama vital, mesmo que insignificante, que trata, por exemplo, a biografemática, essa ciência rasteira, barata e fragmentária o suficiente para articular as relações entre a escrita e a vida, na discrição insuspeita de suas nuances.

[mas é também esse algo, sabemos, aquilo que é caçado nos fragmentos do discurso amoroso, na fotografia, nos fotogramas de Eisenstein. É caçado ou então caça, já que feito fera acuada, surpreende, surge, irrompe da cena e vem quebrar os bons modos do contrato cultural. Nenhum discurso, nenhuma interpretação, nenhum aprofundamento: apenas a carne, sua superficialidade crítica como termômetro].

Em Barthes, escrever é operar com cutelos. É subtrair, retalhar e compor artrologicamente um corpo errático, incapaz de ser apreendido em sua totalidade. Nele, há sempre um excesso, um rastro insignificante, um mais além de todo sentido. Escrevê-lo, assim, é tramar essa miscelânea anti-hierárquica de linguagens e afecções sonoras, literárias, amorosas, cotidianas, imagéticas. É inscrever-se por pancadas, reconhecer-se por pancadas, por saltos, por acentos, por espasmos. Escrevo com o que me toca e rasura as inscrições precedentes. Infiel à minha própria história, escrevo aqui e agora, por obediência exclusiva aos chamados da carne.

\footnotetext{
Ora, não é o corpo, por necessidade, também o corpo do outro? Não sou eu, ao encontrá-lo, aquele que o executa? Corpo: "Todo pensamento, toda comoção, todo interesse suscitado no sujeito amoroso pelo corpo amado" (BARTHES, 2007b, p.93).
}

Sublinhemos: é por amor (e não por um simples assim querer) que vasculho e percorro o corpo do outro, e então sou eu aquele que se inscreve nesses desdobramentos. Seria mesmo preciso dizer: vão aqueles que amo mais longe que os ouvidos, os olhos, a aprendizagem. São eles aqueles que correm pelo corpo, nos músculos e nas vísceras, pelo bater do ritmo. São eles aqueles de quem se pode dizer pertencerem a uma só pessoa, a um só corpo, este corpo que os encontra: "o verdadeiro pianista schumanniano, sou eu" (BARTHES, 2009, p.283); compõe, sonoramente, essa textualidade cotidiana na qual habito. 


\section{3. É sempre em um corpo, pelo corpo, que nos tornamos contemporâneos}

0 corpo: "um simples plural de encantos [...] lugar de pormenores sutis" (CORAZZA, 2013, p.105), canto descontínuo de amabilidades; corpo pulsional, que se empurra e volta a empurrar, passa para outra coisa - pensa noutra coisa; corpo embriagado e suficientemente distraído, estonteado e ardente; corpo de intermezzos, que muda de lugar, muda de postura, impede que o discurso se agarre, engrosse, espalhe-se e desenvolva-se; corpo que se agita e que incomoda a palavra; corpo raso, corpo de acúmulos superficiais, epidermicamente profundo.

Talvez tenhamos que invocar Foucault (2013), para quem o corpo, por condição disperso, encontra na morte, mas também no olhar daquele que se ama a possibilidade de silenciar os seus gritos, serenizar sua utopia. Sob os dedos e os olhos do outro, eis meu corpo, teu corpo, nosso corpo. Escrever com alguém, inscrever-se com alguém: "Escrever aqueles que se ama, testemunhar por eles" (BARTHES, 2005, p.28).

No fundo, talvez o escrever, assim como o amor e a morte, seja esse gesto no qual 0 corpo está aqui: sob o rosto, através dos olhos.

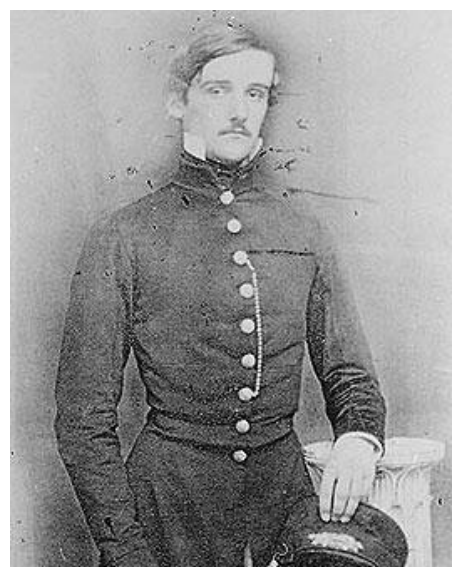

Retomemos, por fim, A câmara clara. De volta a essa obra epílogo, que envolve e acompanha o corpo barthesiano em seu desaparecimento. Lembremo-nos do primeiro olhar que nos é apresentado, o olhar pelo qual a aventura inicia. Lembremo-nos de que se trata de uma obra de olhares, e lembremo-nos do olhar de Robert Mauzi naquele 25 de fevereiro de 1980, o olhar que reúne os traços dispersos do corpo e devolve à imagem lacerada o nome perdido, o mesmo nome que será utilizado nos prontuários médicos do hospital da Salpêtrière.

Lembremo-nos então de Eric Marty $(2009,118)$ frente àquele corpo "preso entre lençóis, tubos, imobilizado no leito médico", o seu silêncio perante a um "herói de ópera, que jaz interminavelmente no palco e cujo esgotamento nos aperta o peito". Lembremo-nos desse testemunho e do medo de que esse mesmo corpo pudesse ler em seus olhos a própria morte.

Lembremo-nos da claridade daquele olhar no jardim de inverno, aquele olhar que não vemos, mas que sabemos, desde sempre, ser ele o responsável pelo encerramento definitivo desse corpo.

Lembremo-nos disso tudo, mas fixemos nosso olhar nesses olhos que viram 0 imperador. Está neles, na força do espanto que causaram, e sobretudo em nossa incapacidade em compartilhar e até mesmo compreender esse espanto, a certeza de que 0 corpo, desde que vivo, é um corpo só.

Porto Alegre, junho de 2015. 


\section{REFERÊNCIAS}

BARTHES, R. Roland Barthes por Roland Barthes. Trad. Leyla Perrone-Moisés. São Paulo: Estação Liberdade, 2003.

- A preparação do romance I: da vida à obra. Trad. Leyla Perrone-Moisés. São Paulo: Martins Fontes, 2005.

Aula. Trad. Leyla Perrone-Moisés. São Paulo: Editora Cultrix, $2007 a$.

- Fragmentos de um discurso amoroso. Trad. Márcia Valéria Martinez de Aguiar. São Paulo: Martins Fontes, 2007b.

o óbvio e o obtuso. Trad. Isabel Pascoal. Lisboa: Edições 70, 2009.

CORAZZA, S. 0 que se transcria em educação? Porto Alegre: UFRGS; Doisa, 2013.

FOUCAULT, M. 0 corpo utópico; Asheterotopias (Trad. Selma TannusMuchail). São Paulo: n-1 Edições, 2013.

MARTY, E. Roland Barthes, o ofício de escrever. Trad. Daniela Cerdeira. Rio de Janeiro: DIFEL, 2009. 